Original Article

\title{
Hydrated Fullerene C60 Decreases Oxidative Damage of Human Bronchial Epithelium Cells DNA
}

\author{
Olga. I. Yablonskaya ${ }^{{ }^{*}}$, Aleksei V. Trofimov ${ }^{1}$, Vladimir L. Voeikov ${ }^{2}$, Elena A. Muratova ${ }^{2}$, Kirill \\ N.Novikov ${ }^{2}$
}

1 Emanuel Institute of Biochemical Physics of Russian Academy of Sciences, Moscow, Russia 2 Biological Faculty of Lomonosov Moscow State University, Moscow, Russia. E-mail:

*olga.yablonsky@gmail.com

\begin{abstract}
Background: Hydrated Fullerene $\mathrm{C}_{60}$ is a 60 carbon atoms symmetrical molecule that can be found in nature. Being transferred into aqueous solution, a hydrophobic $\mathrm{C}_{60}$ establishes Hydrated Fullerene $\mathrm{C}_{60}\left(\mathrm{HyFnC}_{60}\right)$ water solutions that possess oxidation balancing properties in a wide range of concentrations $\left(2.5 \times 10_{-6}-2.5 \times 10_{-19} \mathrm{M}\right)$. Nano-particles of silica $\left(\mathrm{SiO}_{2}\right)$ can initiate reactive oxygen species (ROS) production in aqueous solutions. As silica is a common pollutant and a component of manufactured goods, one of the most probable ways of its penetration into human body is inhalation followed by an increased risk of chronic inflammation and cell degeneration due to ROS production inside the cells and in the extracellular space.

Aims: In this study we focused on the possibility of DNA protection of human bronchial epithelial cells (HBEpCs) of oxidative damage by silica nanoparticles with $\mathrm{HyFnC}_{60}$ in a wide range of concentrations.

Methodology: Cultivated cells were treated with $50 \mathrm{mg} / \mathrm{ml}$ nano-sized SiO2. HBEpCs DNA strand breaks were accessed by comet assay. Intracellular ROS production was measured by DCFH-DA fluorescent spectrophotometry. HyFnclo wete abded the cell culture medium before treatment with silica. The calculated concentratidns by Fin the medium were $1 \times 10-7 \mathrm{M} 1 \times 10-11 \mathrm{M}$, $1 \times 10^{-14} \mathrm{M}$ and $1 \times 10^{-17} \mathrm{M}$. The solutions of $\mathrm{HyFnC}_{60}$ were prepared by 10 - and 100 -fold serial dilutions of $\mathrm{HyFnC}_{60}$ stock solution in pure water. Results were evaluated statistically by Student`s t-test and variance analysis by Statistica ${ }^{\circledR}$ software.

Results and discussion: We have found that in case of pre-treatment of cells with $1 \times 10^{-7} \mathrm{M}$ and $1 \times 10^{-17} \mathrm{M} \mathrm{HyFnC}_{60}$ prior addition of silica DNA damage was decreased. According to DCFH-DA fluorescent microscopy a significant decrease of ROS was observed in case of addition of $\mathrm{HyFnC}_{60}$ to the concentration of $1 \times 10^{-7} \mathrm{M}$ only. In case of simultaneous treatment of cells with silica and $\mathrm{HyFnC}_{60}$ cell damage was decreased at $\mathrm{HyFnC}_{60}$ concentration of $1 \times 10^{-17} \mathrm{M}$. This data proves that DNA was damaged by ROS induced by silica nanoparticles. Moreover, the data confirm that $\mathrm{HyFnC}_{60}$ works as regulator of redox and free radical processes at low concentrations.
\end{abstract}

Key words: DNA oxidation, ultra-low concentrations, hydrated fullerene $\mathrm{C}_{60}, \mathrm{HyFnC}_{60}$, reactive oxygen species, silica, human bronchial epithelial cells, comet assay, water.

Received: March 1, 2018. Accepted: April 26, 2018.

Cite as:. Int J High Dilution Res. 2018;17(2): 43-44. 
(C) International Journal of High Dilution Research. Not for commercial purposes. 